\title{
UKURAN LINGKAR PERGELANGAN TANGAN SEBAGAI INDIKATOR KEGEMUKAN PADA ANAK USIA SEKOLAH DASAR DI KOTA BOGOR JAWA BARAT
}

\author{
Hermina ${ }^{1}$ dan Abas Basuni Jahari ${ }^{1}$ \\ 'Puslitbang Gizi dan Makanan Depkes RI Bogor
}

\begin{abstract}
WRIST CIRCUMFERENCE AS AN INDICATOR FOR OBESITY AMONG PRIMARY SCHOOL CHILDREN IN BOGOR, WEST JAVA
\end{abstract}

Introduction: Obesity is now increasing problem among primary school children. Obesity during childhood has a consequence of obesity in the teen age. Approximately, one third of children with obesity will become obese in their older age.

Objective: To examine the reliability of wrist circumference as an indicator of obesity, particularly for rapid assessment.

Method: The analysis used data from the study on "The development of nutrition education intervention for primary school children from midlle economic class families (2001)". The sample in this study is primary school children age 9-12 years from several favorite schools in the city of Bogor West Java. The weight and height of 1990 children were collected during the study. In addition data of wrist circumference was collected by a simple method non numerical measure but a qualitatif. The method used was by connecting the thumb and the mid-finger of child's right hand on the wrist of child's left hand. The method gives three condition: 1) Normal if the tips of thumb and mid-finger touch each other and no space between wrist and the circle made by the thumb and mid-finger, 2) Thin if the tips of thumb and mid-finger touch each other but there is space between the wrist and the circle, and 3) overweight/obese if the tips thumb and mid-finger does not touch each other. Data on weight and height were converted into z-score weight-for-height (ZWH) based on WHO-NCHS standard, 1982. Kappa coefficient was obtained to evaluate the reliability of wrist circumference to Z-WH in identifying obesity among school children.

Result: $76 \%$ of overweight/obese children and $95 \%$ of non-overweight/obese children could be identified by using wrist circumference. The Kappa coefficient for the reliability test is 0,6 and is a sufficiently reliable.

Conclusion: Wrist circumference could be used as a simple tool for a rapid assesment or sceening of obesity among school children.

Keywords: obesity, wrist circumference, weight-for-height Z-score, school children

\section{PENDAHULUAN}

ari tahun ke tahun, masalah 'gizi lebih' atau kegemukan (overweight dan obesitas) di Indonesia ada kecende-rungan meningkat secara konsisten dengan segala risikonya. Hasil dari beberapa penelitian mengungkapkan bahwa masalah kegemukan ini sudah dialami oleh kelompok penduduk berusia muda. Data Survei
Kesehatan Rumah Tangga tahun 2004 (SKRT 2004) menunjukkan bahwa prevalensi gizi-lebih pada kelompok anak usia 5-12 tahun sebesar 8,5 persen (Balitbangkes, tahun 2005) $)^{(1)}$. Dari kegiatan survei anemia gizi pada anak sekolah dasar di lima wilayah DKI Jakarta tahun 2004 ditemukan sebesar 11,1 persen berstatus gizi lebih, dan ditemukan lebih banyak pada anak laki-laki $(11,6 \%)$ dibandingkan anak perempuan $(10,5 \%)^{(2)}$. 
Hasil penelitian sebelumnya ditemukan bahwa masalah kegemukan pada anak sekolah lebih banyak ditemukan di sekolah favorit dibandingkan dengan sekolah tidak favorit ${ }^{(3,8)}$. Hasil penelitian Hermina dkk. (tahun 2001) yang dilakukan terhadap anak usia sekolah dasar di SD favorit di Kota Bandung menemukan prevalensi gizi lebih sebesar 16,0 persen ${ }^{(3)}$. Penelitian status gizi anak-anak yang dilakukan Wiramiharja, dkk. di kota yang sama pada tahun 1993 menyebutkan bahwa 12 persen anak SD usia di atas 10 tahun dari berbagai tingkat sosial ekonomi ditemukan telah mengalami kegemukan ${ }^{(4)}$. Tampak bahwa dalam kurun waktu lebih dari lima tahun di kota yang sama prevalensi kegemukan pada anak sekolah cenderung meningkat. Demikian pula di Amerika serikat, masalah obesitas dalam kurun waktu lima tahun (1996-2001) cenderung terus meningkat prevalensinya pada usia remaja hingga dewasa muda ${ }^{(5)}$. Kondisi seperti itu tentunya ada kaitannya dengan masalah gizi pada masa kanakkanak dan masa pra-remaja.

Masalah kegemukan pada anak usia sekolah dasar, saat ini perlu mendapat perhatian yang serius. Menurut WHO tahun 2000, penelitian di negara maju menyebutkan bahwa kejadian kegemukan pada orang dewasa, berawal sejak masa kanakkanak yakni 36 persen berawal sejak umur 3-6 tahun dan 55 persen berawal sejak umur 6-10 tahun ${ }^{(6,11)}$.

Kegemukan sering dihubungkan dengan proporsi tubuh individu yakni indeks massa tubuh (IMT) atau ukuran antropometri dengan menggunakan kriteria berat badan (BB) dan tinggi badan (TB) atau disingkat $\mathrm{BB} / \mathrm{TB}$ menurut anjuran WHO-NCHS${ }^{(9)}$.

Selain berat badan dan tinggi badan, saat ini kegemukan dapat diidentifikasi dari ukuran tubuh lainnya seperti lingkar perut, lingkar pinggul, lingkar pinggang atau lingkar ikat pinggang dan yang lainnya terutama pada orang dewasa. Ukuran tubuh tersebut memerlukan alat dan standar yang belum tentu dapat digunakan oleh setiap individu. Oleh karena itu dikembangkan cara sederhana untuk deteksi masalah kegemukan pada anak yaitu ukuran lingkar pergelangan tangan (ULPT) yang dapat diukur oleh anak itu sendiri.

Ukuran lingkar pergelangan tangan anak diduga dapat dijadikan salah satu cara termudah dan termurah untuk mengetahui kegemukan pada anak sekolah. Pada makalah ini disajikan analisis hasil pengukuran lingkar pergelangan tangan anak kaitannya dengan kegemukan yang diukur menggunakan alat antropometri menurut indeks berat badan dan tinggi badan (BB/TB) pada anak usia sekolah dasar.

\section{BAHAN DAN CARA}

Analisis atau kajian ini didasarkan pada data anak sekolah dasar (SD) yang dikumpulkan dalam penelitian "Pengembangan intervensi pendidikan gizi untuk anak usia sekolah dasar pada keluarga menengah di perkotaan".

Penelitian tersebut dilakukan pada tahun 2001 di Kota Bogor, Jawa Barat dengan mengambil sampel murid SD kelas 5 dan 6 (usia 9-12 tahun) di sekolah dasar yang dianggap favorit $(n=1990)^{(7)}$.

Sembilan SD favorit yang diteliti adalah: SD-RP, SDN-P4, SDN-P1, SDN-S2, SDNB3, SD-P, SDN-BT2, SD-TH dan SD-BI, yang berlokasi di lima kecamatan di Kota Bogor yakni kecamatan Bogor Barat, Bogor Selatan, Bogor Timur, Bogor Tengah dan Tanah Sareal.

Di antara data yang dikumpulkan dalam penelitian tersebut, data yang digunakan untuk analisis ini adalah berat badan (BB), tinggi badan (TB), tanggal lahir, tanggal diukur TB dan ditimbang BB, jenis kelamin dan lingkar pergelangan tangan kiri anak. Berat badan ditimbang dengan timbangan digital 'Seca' dengan ketelitian 0,1 kg. Sedangkan tinggi badan diukur menggunakan microtoice dengan ketelitian $0,1 \mathrm{~cm}$. Umur anak dihitung berdasarkan tanggal lahir dan tanggal pengukuran. Ukuran lingkar pergelangan tangan anak diukur dengan melingkarkan ibu jari dan jari tengah tangan kanan, ke pergelangan tangan kiri yang dilakukan oleh murid yang 
bersangkutan dengan pengamatan tim peneliti.

Hasil pengukuran pergelangan tangan anak dinilai secara kualitatif dengan skala ordinal 1 sampai 3. Masing-masing kategori adalah sebagai berikut:

1. Kategori 1: Normal, jika ibu-jari dan jaritengah dilingkarkan pada pergelangan tangan kiri dapat bersentuhan satu sama lain. Atau tidak ada jarak antara pergelangan tangan dengan lingkaran yang dibuat oleh ibu-jari dan jari-tengah (pas/tidak-longgar).

2. Kategori 2: Kurus, jika ibu-jari dan jaritengah dilingkarkan pada pergelangan tangan kiri dapat bersentuhan satu sama lain, tapi ada jarak antara pergelangan tangan dengan lingkaran yang dibuat oleh ibu-jari dan jari-tengah (longgar).

3. Kategori 3: Overweight/obes, jika ibujari dan jari-tengah dilingkarkan pada pergelangan tangan kiri tidak dapat bersentuhan satu sama lain (renggang).

Data berat dan tinggi badan dikonversikan menjadi nilai Z-Score menurut baku WHO-NCHS. Nilai Z-Score ini kemudian digunakan untuk menilai status kegemukan anak, yaitu:

1. Kurus; bila nilai Z-Score $<-2 S D$

2. Normal; bila nilai Z-Score $\geq-2$ SD dan $\leq$ 2 SD

3. Risiko gemuk (overweight); bila nilai ZScore $>2$ SD dan $\leq 3$ SD
4. Berat badan lebih (gemuk/obes); bila nilai Z-Score $>3$ SD

Untuk mengukur hubungan antara variabel independen (ukuran lingkar pergelangan tangan) dengan variabel dependen (status kegemukan pada anak) dilakukan analisis bivariat dengan menggunakan uji statistik Pearson Chi square. Sedangkan untuk menguji reliabilitas pengukuran pergelangan tangan murid dengan pengukuran status kegemukan dilakukan uji measure of agreement Kappa.

\section{HASIL DAN BAHASAN}

\section{Keadaan Gizi Murid}

Secara keseluruhan murid SD yang diteliti berumur antara 9-12 tahun. Jumlah murid laki-laki dan perempuan berimbang. Keadaan gizi murid di sembilan SD favorit yang diteliti sebagian besar adalah normal $(89,6 \%)$ menurut Z-Score BB/TB. Sebanyak 2,7 persen kurus dan 7,7 persen berstatus gizi lebih $(5,0 \%$ beresiko gemuk/overweight dan $2,7 \%$ gemuk/obes).

Murid laki-laki lebih banyak yang beresiko gemuk $(8,1 \%)$ dibanding murid perempuan $(2,0 \%)$, demikian pula lebih banyak murid laki-laki yang gemuk $(4,9 \%)$ dibanding murid perempuan (0,5\%), disajikan pada Tabel 1. Nilai Z-Score indeks $\mathrm{BB} / \mathrm{TB}$, rata-rata adalah $0,09 \pm 1,26$ dengan rentang nilai terendah $-3,1$ dan nilai tertinggi 7,0 standar deviasi Z-Score BB/TB.

Tabel 1

Distrubusi Murid Berdasarkan Jenis Kelamin dan Status Gizi dengan Indeks Berat Badan menurut Tinggi Badan (BB/TB)

\begin{tabular}{|l|c|c|c|c|c|c|c|c|c|c|}
\hline \multirow{3}{*}{ Jenis kelamin } & \multicolumn{10}{|c|}{ Status gizi menurut indeks BB/TB } \\
\cline { 2 - 12 } & \multicolumn{2}{|c|}{ Kurus } & \multicolumn{2}{c|}{ Normal } & \multicolumn{2}{c|}{ Resiko gemuk } & \multicolumn{2}{c|}{ Gemuk } & \multicolumn{2}{c|}{ Jumlah } \\
\cline { 2 - 11 } & $\mathrm{n}$ & $\%$ & $\mathrm{n}$ & $\%$ & $\mathrm{n}$ & $\%$ & $\mathrm{n}$ & $\%$ & $\mathrm{n}$ & $\%$ \\
\hline Laki-laki & 28 & 2,9 & 823 & 84,2 & 79 & 8,1 & 48 & 4,9 & 978 & 100 \\
\hline Perempuan & 26 & 2,6 & 961 & 95,0 & 20 & 2,0 & 5 & 0,5 & 1012 & 100 \\
\hline Jumlah & 54 & 2,7 & 1784 & 89,6 & 99 & 5,0 & 53 & 2,7 & 1990 & 100 \\
\hline
\end{tabular}

Tabel 2 menunjukkan bahwa kejadian kegemukan pada murid SD usia 9-12 tahun lebih banyak diderita oleh murid laki-laki
$(13,0 \%)$ dibanding murid perempuan $(2,5 \%)$. Dari Tabel 2 terlihat bahwa jenis kelamin sangat berkaitan dengan kegemukan pada 
murid SD usia 9-12 tahun $(p<0,001)$. Murid laki-laki mempunyai risiko 6 kali menderita kegemukan dibanding murid perempuan (OR=5,89; $\quad 95 \% \mathrm{Cl}=3,80-9,14 ; \quad \mathrm{p}=0,000)$. Kondisi seperti ini sama dengan yang diungkapkan dalam survey anemia gizi pada anak usia sekolah dasar di DKI Jakarta (2004), yang menemukan bahwa murid yang berstatus gizi lebih, banyak ditemukan pada murid laki-laki dibanding murid perempuan (2).

Tabel 2

Distribusi Murid Berdasarkan Jenis Kelamin dan Status Gizi dengan Indeks Berat Badan menurut Tinggi Badan (BB/TB)

\begin{tabular}{|l|c|c|c|c|c|c|}
\hline \multirow{3}{*}{ Jenis kelamin } & \multicolumn{4}{|c|}{ Status Kegemukan } & \multicolumn{2}{c|}{ Jumlah } \\
\cline { 2 - 7 } & Gemuk & \multicolumn{2}{|c|}{ Tidak Gemuk } & \multicolumn{2}{c|}{} \\
\cline { 2 - 7 } & $\mathrm{n}$ & $\%$ & $\mathrm{n}$ & $\%$ & $\mathrm{n}$ & $\%$ \\
\hline Laki-laki & 127 & 13,0 & 851 & 87,0 & 978 & 100 \\
\hline Perempuan & 25 & 2,5 & 987 & 97,5 & 1012 & 100 \\
\hline Jumlah & 152 & 7,6 & 1838 & 92,4 & 1990 & 100 \\
\hline$X^{2}=77,952$ df $=1$ & $p=0,000$ & OR: 5,89 & $95 \%$ Cl: $3,80-9,14 ; \quad p=0,000$
\end{tabular}

\section{Hubungan Pergelangan Tangan dengan Status Kegemukan}

Tabel 3 menunjukkan bahwa pada kondisi gizi murid risiko gemuk dan gemuk, maka pergelangan tangannya cenderung besar. Bila pergelangan tangan kiri muridmurid tersebut diukur dengan lingkaran ibujari dan jari-tengah tangan kanannya sendiri, maka lingkaran jari-jari tersebut akan renggang. Sebagian besar murid yang ukuran lingkar pergelangan tangannya
(ULPT) renggang, termasuk dalam kategori status gizi 'gemuk' menurut indeks BB/TB. Sementara itu bila ULPT murid yang tidak renggang (longgar atau pas) termasuk kategori status gizi normal dan kurus (menurut indeks BB/TB). Dari Tabel 3 tersebut tampak bahwa hasil pengukuran ULPT sangat berhubungan dengan hasil pengukuran $\mathrm{BB} / \mathrm{TB}$ menurut indeks $\mathrm{BB} / \mathrm{TB}$ $(p<0,001)$.

Tabel 3

Distribusi Status Gizi Murid menurut Indeks BB/TB dan Ukuran Lingkar Pergelangan Tangan (ULPT)

\begin{tabular}{|l|c|c|c|c|c|c|c|c|c|c|}
\hline \multirow{2}{*}{$\begin{array}{c}\text { Status gizi } \\
\text { menurut } \\
\text { ULPT }\end{array}$} & \multicolumn{10}{|c|}{ Status gizi menurut indeks BB/TB } \\
\cline { 2 - 12 } & \multicolumn{2}{|c|}{ Kurus } & \multicolumn{2}{c|}{ Normal } & \multicolumn{2}{c|}{ Risiko gemuk } & \multicolumn{2}{c|}{ Gemuk } & \multicolumn{2}{c|}{ Total } \\
\cline { 2 - 12 } & $\mathrm{n}$ & $\%$ & $\mathrm{n}$ & $\%$ & $\mathrm{n}$ & $\%$ & $\mathrm{n}$ & $\%$ & $\mathrm{n}$ & $\%$ \\
\hline Kurus & 53 & 3,6 & 1395 & 95,8 & 8 & 0,5 & 0 & 0 & 1456 & 100 \\
\hline Normal & 1 & 0,3 & 291 & 90,9 & 26 & 8,1 & 2 & 0,6 & 320 & 100 \\
\hline Gemuk & 0 & 0 & 98 & 45,8 & 65 & 30,4 & 51 & 23,8 & 214 & 100 \\
\hline Jumlah & 54 & 2,7 & 1784 & 89,6 & 99 & 5,0 & 53 & 2,7 & 1990 & 100 \\
\hline
\end{tabular}

Pada Tabel 4 terdapat hubungan antara status kegemukan dengan ukuran pergelangan tangan anak $(p<0,001)$. Dari tabel tersebut murid yang gemuk menurut ZScore BB/TB sebanyak 76,3\% ( $n=116)$ dapat teridentifikasi oleh pergelangan tangannya. Demikian juga murid yang tidak gemuk menurut Z-Score BB/TB sebanyak 94,7\% $(n=1740)$ teridentifikasi oleh pergelangan tangannya. 
Tabel 4 menunjukkan pula bahwa murid-murid yang gemuk (berisiko gemuk dan gemuk) mempunyai risiko 57 kali lebih besar pergelangan tangannya dibanding dengan murid yang tidak gemuk (OR=57,2; $95 \% \mathrm{Cl}=37,4-87,6 ; p=0,000)$.

Sebaliknya bila murid itu 'tidak gemuk' menurut Z-Score BB/TB (kurus dan normal), maka ukuran lingkar pergelangan tangannya relatif kecil/sedang, dan ukuran lingkar jari tangan kanan di pergelangan tangan kirinya 'tidak renggang' atau ujung jari tersebut saling bersentuhan (longgar atau pas). Bila ULPT 'tidak renggang' maka status gizi menurut ULPT adalah 'tidak gemuk'.

Dalam Tabel 4 tersebut tampak pula bahwa koefisien Kappa sebagai derajat reliabilitas antara kedua indikator yakni status gizi menurut ULPT dan menurut ZScore BB/TB adalah cukup kuat dan cukup reliable (Kappa $=0,598$ std. $\quad \mathrm{E} .=0,031$ $p=0,000)$.

Tabel 4

Hubungan Antara Status Kegemukan menurut Z-Score BB/TB dan Ukuran Lingkar Pergelangan Tangan (ULPT) pada Murid Usia 9-12 Tahun

\begin{tabular}{|c|c|c|c|c|c|c|}
\hline \multirow{3}{*}{$\begin{array}{c}\text { Status Kegemukan } \\
\text { menurut Ukuran Lingkar } \\
\text { Pergelangan Tangan }\end{array}$} & \multicolumn{4}{|c|}{$\begin{array}{c}\text { Status Kegemukan menurut } \\
\text { Z-Score BB/TB }\end{array}$} & \multirow{2}{*}{\multicolumn{2}{|c|}{ Jumlah }} \\
\hline & \multicolumn{2}{|c|}{ Gemuk } & \multicolumn{2}{|c|}{ Tidak Gemuk } & & \\
\hline & $n$ & $\%$ & $n$ & $\%$ & $\mathrm{n}$ & $\%$ \\
\hline Gemuk (ULPT renggang) & 116 & 76,3 & 98 & 5,3 & 214 & 100 \\
\hline Tidak Gemuk (ULPT tdk renggang) & 36 & 23,7 & 1740 & 94,7 & 1776 & 100 \\
\hline Jumlah & 152 & 7,6 & 1838 & 92,4 & 1990 & 100 \\
\hline
\end{tabular}

Pada Tabel 4 dapat dilihat lebih jelas bahwa sebanyak $76,3 \%$ murid yang gemuk menurut Z-Score BB/TB mempunyai ukuran lingkar pergelangan tangan (ULPT) yang renggang. Sementara itu $94,7 \%$ murid yang tidak gemuk ULPTnya tidak renggang.

\section{KESIMPULAN}

\section{Kesimpulan}

Ukuran lingkar pergelangan tangan (ULPT) murid sangat berkaitan dengan kegemukan. Murid yang berstatus gizi lebih atau gemuk (risiko gemuk dan gemuk), ukuran lingkar pergelangan tangannya lebih besar dibanding dengan murid yang tidak gemuk.

Sebanyak $76,3 \%$ murid yang gemuk dan $94,7 \%$ murid yang tidak gemuk menurut Z-Score BB/TB dapat teridentifikasi oleh pergelangan tangannya. Koefisien 'Kappa' sebagai ukuran derajat reliabilitas antara kedua indikator kegemukan (menurut ZScore BB/TB dan ULPT) cukup kuat dan reliable sebagai indikator pengukuran status kegemukan (kappa=0,598).

Dari hasil analisis ini dapat disimpulkan bahwa ukuran lingkar pergelangan tangan (ULPT) kiri seorang anak yang diukur dengan lingkaran antara ujung ibu-jari dan jari-tengah tangan kanan anak yang bersangkutan, dapat digunakan sebagai alat atau indikator untuk penapisan kegemukan pada anak sekolah. Bila ukuran lingkar pergelangan tangan (ULPT) anak 'gemuk' atau masuk dalam kategori 3 (ULPT renggang) maka anak tersebut termasuk gemuk dan perlu dikonfirmasi lebih lanjut dengan pemeriksaan antropometri dan kesehatannya).

\section{Saran}

Hasil penelitian ini perlu dikaji lebih lanjut dengan melakukan uji-coba 
pengukuran lingkar pergelangan tangan (ULPT) pada populasi di tempat yang berbeda dengan cakupan yang lebih besar, agar ULPT pada anak usia sekolah dapat digunakan sebagai salah satu cara termudah dan termurah untuk mengidentifikasi kegemukan pada anak sekolah.

\section{RUJUKAN}

1. Badan Litbang Kesehatan Dep.Kes. RI. Survei Kesehatan Rumah Tangga tahun 2004 (SKRT 2004). Volume 2, 2005.

2. Dinkes Provinsi DKI Jakarta dan Puslitbang gizi \& makanan. Survei Anemia Gizi pada Anak Sekolah Dasar di DKI Jakarta tahun 2004. Jakarta, 2004.

3. Hermina, Nurfi Afriansyah, Trintrin $T$. Mudjianto, Tjetjep S. Hidayat dan Abas B. Jahari. Pengembangan Materi Pesan-Pesan Gizi untuk Pencegahan dan Penanggulangan Masalah Kegemukan pada Usia Dini. Pusat Penelitian dan Pengembangan Gizi dan Makanan, 2001. Laporan Penelitian.

4. Wiramiharja, K.K. Kondisi gizi anak sekolah dasar umur 10-13 tahun di Kodya Bandung. MKB 1993,25.

5. Penny Gordon-Larsen, al. all. Five-Year Obesity incidence in the Transition Period between Adolescence and
Adulthood: The National Longitudinal Study of Adolescencet Health. Am. Journal Clinical Nutrition, 2004:80:569575.

6. Inoue, S. and Zimmet, P. at all. The Asia-Pacific perspective: Redefining Obesity and its Treatment. IASO. WHO. February 2000.

7. Hermina, Nurfi Afriansyah, Tjetjep S. Hidayat, Trintrin T. Mudjianto dan Abas B. Jahari. Pengembangan intervensi pendidikan gizi untuk anak usia sekolah dasar pada keluarga menengah di perkotaan. Badan Penelitian dan Pengembangan Kesehatan Dep Kes RI., 2002. Laporan Penelitian Risbinkes.

8. Irawati, A., dkk., Status Gizi Murid Taman Kanak-Kanak dan Sekolah Dasar di Sekolah Favorit dan Bukan Favorit. Penelitian Gizi dan Makanan. 1992. 14:25-34.

9. WHO. Measuring Change in Nutritional Status. Geneva: WHO, 1983.

10. Lohman G. Timothy, Alex F. Roche dan Reynaldo Martorell. Antropometric standardization reference manual. Champaign, Illinois. Human Kinetics Books. s.a.

11. Whitaker et al. Tracking BMl-for-age birth to 18 years with persent of overweight children who are obese at age 25. NEJM: 1997;337:869-873. 